\title{
MALDI Mass Spectrometry of Small Molecules Using Nanometer- sized Clay
}

\author{
Jiawei Xu, $* * *$ Junko N. Kondo, ${ }^{* * *}$ and Tatsuya FuJINo*,**† \\ *Department of Applied Chemistry, Graduate School of Science and Engineering, Toyo University, 2100 Kujirai, \\ Kawagoe 350-8585, Japan \\ **Bio-Nano Electronics Research Centre, Toyo University, 2100 Kujirai, Kawagoe 350-8585, Japan \\ ***Laboratory for Chemistry and Life Science, Institute of Innovative Research, Tokyo Institute of Technology, \\ 4259 Nagatsuta, Midori, Yokohama 226-8503, Japan
}

\begin{abstract}
Nanometer-sized clay, allophane, was used as the matrix for matrix-assisted laser desorption ionization mass spectrometry (MALDI MS) and applied to the ionization of small molecules. First, the laser desorption ionization mass spectrum of cation-exchanged allophane was measured, and it was found that the cation exchange proceeded smoothly with increasing atomic number of alkali metals in the periodic table. This phenomenon was explained by considering the size of the counter anion on the allophane surface. Then, fructose was measured as the analyte using each alkali-cation-exchanged allophane as the matrix. Contrary to the measurements using allophane itself, the peak intensity of fructose decreased with increasing atomic number of alkali metals in the periodic table. This phenomenon was clarified by considering the stability of alkali cation in the presence of a surface anion, the desorption energy, and the solvation enthalpy of each alkali cation. The applicability of allophane to high molecular weight compounds was also confirmed by measuring cyclodextrin, angiotensin II, and insulin. Finally, a combination of allophane and zeolite was examined by assuming proton relay among allophane, zeolite, and analyte. As a result of proton supply from zeolite to allophane, the peak intensity of the proton sponge (1,8-bis(dimethylamino)naphthalene) was enhanced by almost 2.2 times.
\end{abstract}

Keywords Allophane, MALDI, nano, zeolite

(Received June 5, 2019; Accepted August 21, 2019; Advance Publication Released Online by J-STAGE August 30, 2019)

\section{Introduction}

Matrix-assisted laser desorption ionization (MALDI) is a soft ionization method that features minimal analyte decomposition during the ionization process. MALDI combined with a mass spectrometer, MALDI MS, enables the detection of nonvolatile compounds. ${ }^{1}$ Such organic matrix molecules as $\alpha$-cyano-4hydroxycinnamic acid (CHCA), sinapinic acid (SA), 2,5-dihydroxybenzoic acid (DHB), and 2,4,6-trihydroxyacetophenone (THAP) are often used. Upon laser irradiation, however, those matrix molecules sometimes decompose, yielding many fragment peaks particularly in the low mass region. Therefore, it is known that the application of MALDI MS to low molecular weight compounds is difficult. Other problems, such as low ionization efficiency and protonated analyte peak suppression by alkali metal ion contaminants, have been also pointed out.

To overcome these drawbacks, many attempts have been made, including the use of matrix-free techniques, ${ }^{2-5}$ the application of nanometer-sized particles, ${ }^{6-10}$ and the use of a co-matrix with conventional organic matrix molecules. ${ }^{11-15}$ Recently, we have reported that zeolite may be one of the useful additives in MALDI MS. Zeolites are crystalline aluminosilicates with three-dimensional frameworks and nanometer-order cages.

† To whom correspondence should be addressed.

E-mail: fujino048@toyo.jp
Hydroxyl groups having strong Brönsted acidity exist on the zeolite surface. It was found that by combining an organic or inorganic matrix with zeolite, the dissociation of matrix molecules was prevented and the peak intensity of the analyte was enhanced. ${ }^{16}$ Although zeolite is useful for MALDI MS, the addition of an organic or inorganic matrix is necessary because zeolite has no absorption coefficient in the UV-vis region.

In this study, we focused on one of the clays, allophane. ${ }^{17}$ Allophane is a poorly crystalline aluminosilicate; it is a weathering or hydrothermal alteration product of volcanic glass or feldspar. Allophane is a nanometer-sized particle measuring around $5 \mathrm{~nm}$ in diameter. A hollow space exists inside the particle and through-holes of 0.3 to $0.5 \mathrm{~nm}$ are found on the particle wall. As hydroxyl groups exist around the throughholes, allophane shows high affinity to water molecules and possesses exchangeable alkali cations, as in the case of zeolites. As allophane is a nanometer-sized particle, it has an absorption coefficient in the UV-vis region because of the quantum size effect. Therefore, we assumed that allophane itself could be used as a matrix in MALDI MS. In this report, we discussed the utility of allophane as a matrix through MALDI MS measurements of small molecules and insulin protein. It is noted that allophane is an insulator and the ionization process is different from other metal-oxide semiconductor matrices like $\mathrm{TiO}_{2}$ and $\mathrm{ZnO}$. Here, we used allophane as a catalyst possessing proton and alkali cations and transferring them according to the chemical reactions as in the case of zeolite. As it is known that 
allophane has weak acidity, its combined use with zeolite was also examined. Analyte peak intensity enhancement was achieved by proton relay among zeolite, allophane, and analyte.

\section{Experimental}

Allophane was purchased from Sinagawa Kasei, and the physicochemical property is described elsewhere. ${ }^{17}$ The cation exchange of allophane was carried out by referring to the cation exchange of zeolite. ${ }^{18}$ Briefly, the acetate of each of the alkali metals ( $\mathrm{Li}, \mathrm{Na}, \mathrm{K}, \mathrm{Rb}$, and $\mathrm{Cs}$ ) was dissolved in distilled water to obtain a $300-\mathrm{mL}$ acetate solution of $2.0 \mathrm{~mol} \mathrm{~L}^{-1}$ concentration. One gram of allophane was added to the acetate solution $(100 \mathrm{~mL})$ and the mixture was stirred for $1 \mathrm{~h}$ at $343 \mathrm{~K}$. The mixture was filtered at room temperature. Thus-treated allophane was dissolved again in the acetate solution and the mixture was stirred for $1 \mathrm{~h}$ at $353 \mathrm{~K}$. This treatment was repeated three times. Finally, $\mathrm{Li}^{+}-, \mathrm{Na}^{+}-, \mathrm{K}^{+}-, \mathrm{Rb}^{+}$, and $\mathrm{Cs}^{+}-$ exchanged allophanes (LiAlp, NaAlp, KAlp, RbAlp, and CsAlp) were obtained. Proton exchange of allophane was carried out by using $\mathrm{HCl}$ aqueous solution $\left(2.0 \mathrm{~mol} \mathrm{~L}^{-1}\right)$. One gram of allophane was added to $\mathrm{HCl}$ solution $(100 \mathrm{~mL})$ and the mixture was stirred for $1 \mathrm{~h}$ at $343 \mathrm{~K}$. The mixture was filtered at room temperature. Thus-treated allophane was dissolved again in the $\mathrm{HCl}$ solution, and the mixture was stirred for $1 \mathrm{~h}$ at $353 \mathrm{~K}$. This treatment was repeated three times and $\mathrm{H}^{+}$-exchanged allophane (HAlp) was obtained. Allophane as received or one of the treated allophanes $(4 \mathrm{mg})$ was suspended in a 1-mL solution of acetonitrile and water $(7: 3 \mathrm{v} / \mathrm{v})$. One microliter each of allophane and analyte solution was pipetted onto a stainless steel plate, left in air for a few minites to evaporate the solvent, and analyzed by a commercial MALDI-TOF mass spectrometer (Bruker) equipped with a nitrogen laser operating at $337 \mathrm{~nm}$. The instrument was operated in the positive ion mode and spectra were acquired with a reflectron. Mass spectra were obtained by averaging 200 laser shots at random sample spots. Excitation laser power was $24 \mu \mathrm{J}$ except when cyclodextrin $(36 \mu \mathrm{J})$, angiotensin II $(36 \mu \mathrm{J})$, and insulin $(64 \mu \mathrm{J})$ were detected. X-ray photoelectron spectroscopy (XPS) was performed by using a commercial apparatus (SmartLab, Rigaku). Allophane was dispersed in methanol and dropped onto a Si plate with Au deposition. Al $K \alpha$ line was used for excitation.

\section{Results and Discussion}

Figure 1(a) shows the XPS spectrum of allophane. Asterisks are peaks related to Au deposited on the Si substrate. The peaks of elemental Si (16.25\%), Al (32.04\%), and O (47.48\%) were observed. Although a very weak peak of carbon (C) was observed $(4.23 \%)$, this was considered to originate in the residual solvent (methanol) used for the preparation. It was confirmed from Fig. 1(a) that allophane is composed of only $\mathrm{Si}$, $\mathrm{Al}$, and $\mathrm{O}$. In the diffuse reflectance spectrum in Fig. 1(b), allophane has an absorption in the UV-vis region. However, allophane is an aluminosilicate and does not contain elements having an absorption in the UV-vis region. This absorption is due to the quantum size effect; as a result of electron confinement in the nanometer-sized particles, the band gap energy is different from that of the bulk. As allophane has an absorption coefficient at $337 \mathrm{~nm}$ (excitation wavelength), it was assumed that allophane itself could be used as a matrix for MALDI MS without using any additional matrix molecules. In the next step, the utility of
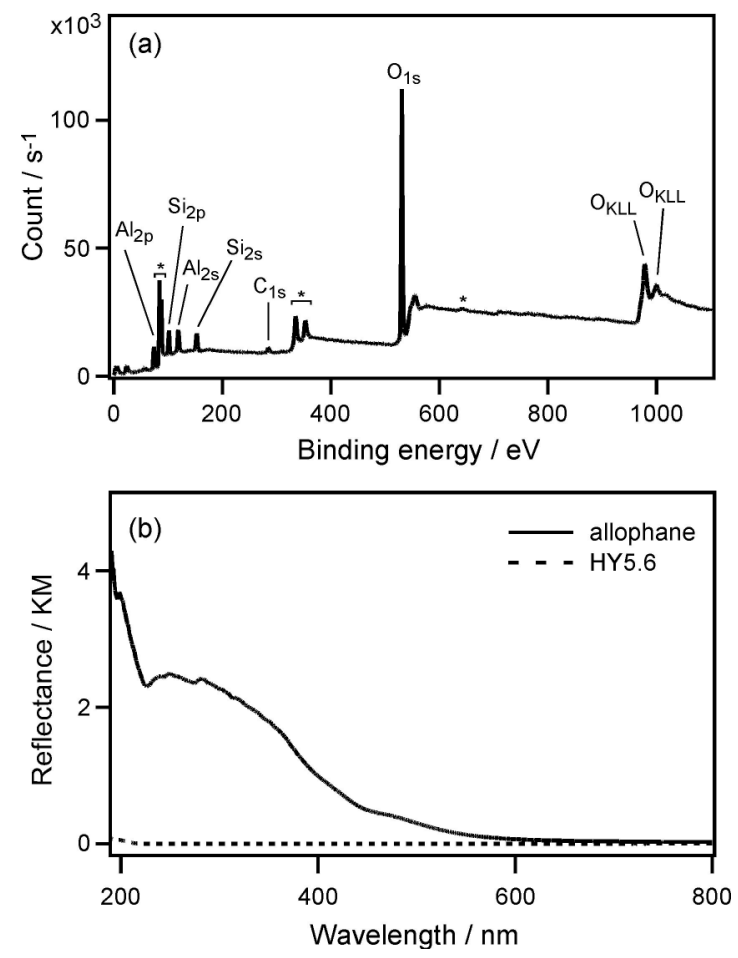

Fig. 1 (a) XPS spectrum of allophane. (b) Diffuse reflectance spectrum of allophane. Spectrum of HY5.6 is also shown for comparison.

allophane as the matrix for MALDI MS was investigated.

Figure 2(a) shows the laser desorption ionization mass spectrum of allophane itself without any pretreatment or cation exchange. As allophane possesses many alkali cations, peaks of $\mathrm{Na}^{+}$and $\mathrm{K}^{+}$were mainly observed upon photoexcitation, although other noise peaks were noted in the mass region less than $m / z=100$. Cation exchange yielded peaks of other alkali cations as well, as shown in Figs. 2(b) to 2(f). Considering the peak intensities of all the alkali cations observed in each spectrum, the substitution ratio was roughly estimated as follows: $20.1 \%$ for LiAlp, $78.7 \%$ for NaAlp, $99.4 \%$ for KAlp, 98.0 for RbAlp, and 99.2 for CsAlp. The substitution proceeded smoothly and the peak intensities of the alkali cations increased with increasing atomic number of alkali metals in the periodic table. The hydroxyl group is a hard base whereas alkali cations are hard acids. Judging from the HASB (Hard and Soft Acids and Bases) theory, the substitution of an alkali cation with a small ionic radius, such as $\mathrm{Li}^{+}$or $\mathrm{Na}^{+}$, for a hydroxyl group is considered favorable. However, the results in Fig. 2 show the opposite. The reason for this is considered as follows. In the case of cation substitution for hydroxyl groups on the solid surface, several lattice oxygens become counter anions and the electrons responsible for the negative charge are delocalized over those oxygens. In the case of silica, for example, the counter anion is expressed as $\mathrm{SiO}_{4}^{-}$. In this situation, it is considered that an electronegative charge does not exist at one point but is spread over a large area, and therefore an alkali cation with a large ionic radius stabilizes the surface counter anion effectively. Consequently, the substitution of an alkali cation with a large ionic radius proceeds smoothly. In the case of zeolite, the delocalization of surface electrons is more remarkable; four oxygen atoms around an $\mathrm{Al}$ atom receive a negative charge as the counter anion of Brönsted proton. At low 


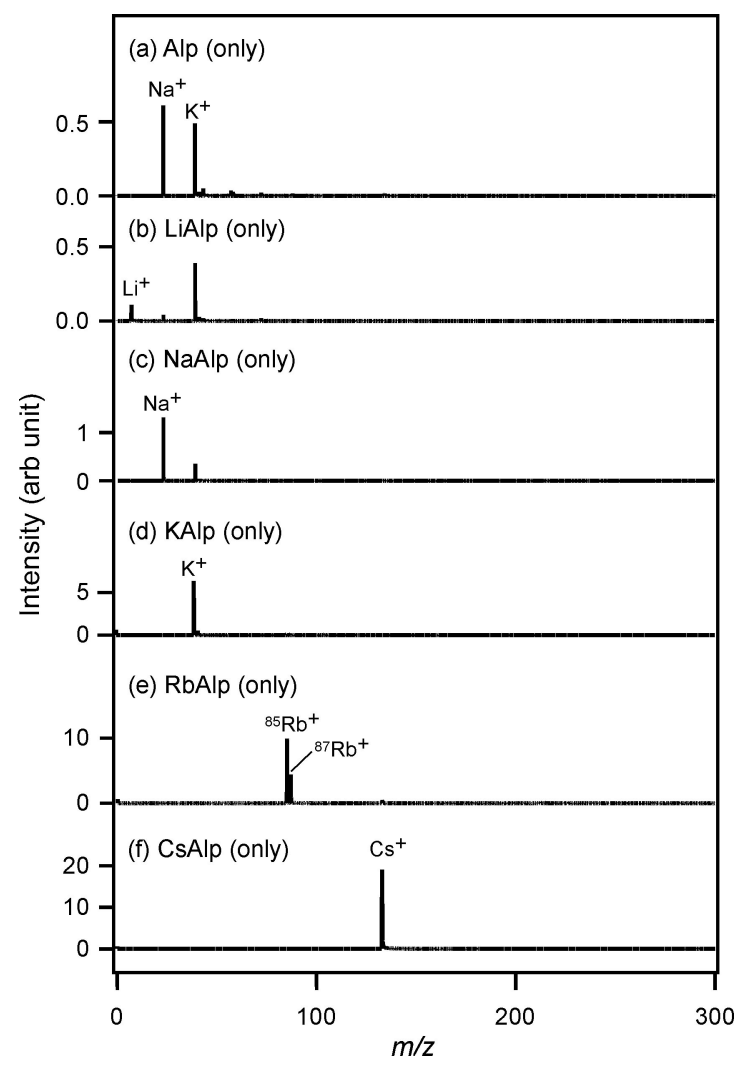

Fig. 2 (a) Mass spectrum of allophane (Alp) itself without any pretreatment or cation exchange. Mass spectra of allophane after cation exchange; (b) $\mathrm{Li}^{+}$-exchanged (LiAlp), (c) $\mathrm{Na}^{+}$-exchanged (NaAlp), (d) $\mathrm{K}^{+}$-exchanged (KAlp), (e) $\mathrm{Rb}^{+}$-exchanged (RbAlp), and (f) $\mathrm{Cs}^{+}$-exchanged allophane (CsAlp).

temperatures, a covalent bond would be formed between the most stable oxygen and a hydrogen atom to generate a hydroxyl group. As the energy difference among the four oxygen atoms is not so large, it was reported by Kondo and coworkers that the hydrogen atom moves from site to site at high temperatures. ${ }^{19}$ This is one reason why the IR bandwidth of $\mathrm{OH}$ stretching vibration shows broadening and a red shift with increasing temperature.

In order to confirm the ability of allophane as the matrix for MALDI MS, the saccharide fructose (Fru) was measured with LiAlp, NaAlp, KAlp, RbAlp, and CsAlp, and the results are shown in Fig. 3. Contrary to the peak intensity of each alkali cation shown in Fig. 2, the peak intensity of alkali-cationadducted analyte decreased with increasing period of alkali cations. In addition, many noise peaks were observed in the spectra of Fru with RbAlp and CsAlp. We present the following reasons to explain the results in Fig. 3. (1) Based on the argument in Fig. 2, the bond between alkali cation and surface counter anion became stable with increasing period of alkali cations. Therefore, it was easily assumed that the removal of alkali cations, such as $\mathrm{Rb}$ and $\mathrm{Cs}$, became difficult. In addition, (2) much energy would be necessary for the desorption of heavy alkali cation-adducted species. As the energy necessary for the desorption of a heavy analyte becomes large, the energy available for the molecular desorption becomes small because the initial input energy by the photoexcitation is the same. However, this does not mean that allophane could not be used as the matrix for high molecular weight analytes. Figure 4(a) shows the spectra of $\alpha$-cyclodextrin $(\alpha$-CD) measured with

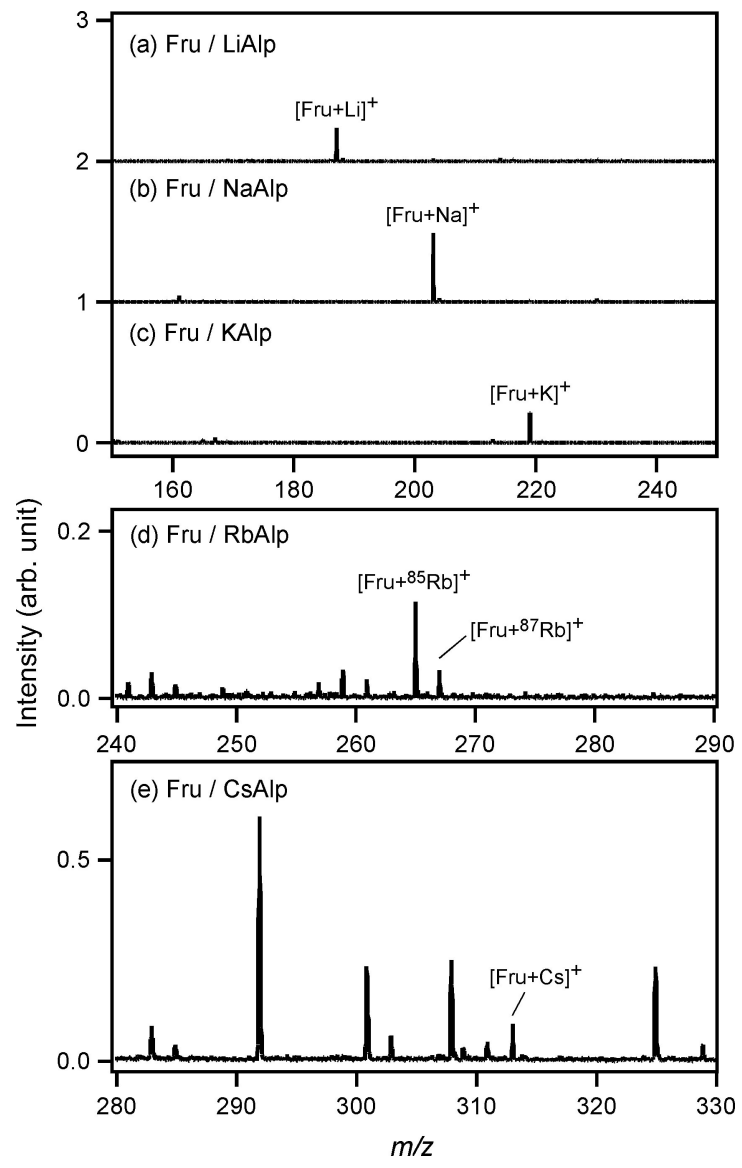

Fig. 3 Mass spectra of fructose (Fru) measured with (a) LiAlp, (b) NaAlp, (c) KAlp, (d) RbAlp, and (e) CsAlp.

NaAlp. Although the laser power should be increased to $36 \mu \mathrm{J}$, the peak of $[\alpha-\mathrm{CD}+\mathrm{Na}]^{+}$was observed at $m / z=996$. Figures 4(b) and 4(c) show the spectra of angiotensin II (Ang) and insulin (Ins) measured with NaAlp. As in the case of $\alpha$-CD, the laser power should be increased to $36 \mu \mathrm{J}$ for Ang and $64 \mu \mathrm{J}$ for Ins; however, both molecules were ionized at $\mathrm{m} / z=1069$ and 5830. Although the peak intensity of Ins was barely more than three times the noise level, we could say that Ins was ionized by using allophane. However, it should be noted that allophane has less ability for the ionization of large molecules rather than small molecules at this stage.

The results and reproducibility of Fig. 3 are summarized in Table 1. In Table 1 , the peak intensity of $[\mathrm{Fru}+\mathrm{M}]^{+}(\mathrm{M}=$ alkali metal cation) obtained from LiAlp, NaAlp, KAlp, RbAlp, and CsAlp are summarized. The average values, the standard deviation (SD) and the relative standard deviation (RSD) of three different measurements (Seq. 1-3) were shown. SD overall and RSD overall are the averaged values of SD and RSD obtained from measurements using each alkali-cation-exchanged allophane. Overall value of RSD (RSD overall) was 27\%, which was almost equal to that of conventional MALDI MS. Therefore, it is understood that allophane itself does not have the function of improving reproducibility as allophane is a nanometer-sized particle, unlike zeolite. For an additional explanation of the results in Fig. 3, the (3) solvation enthalpy of each alkali cation seemed important. Although the substitution ratio of $\mathrm{Li}^{+}$was small $(20.1 \%)$ in Fig. 2, the peak intensity of $[\mathrm{Fru}+\mathrm{Li}]^{+}$was as high as that of $[\mathrm{Fru}+\mathrm{K}]^{+}$. As it was assumed that water molecules on the allophane surface played an 

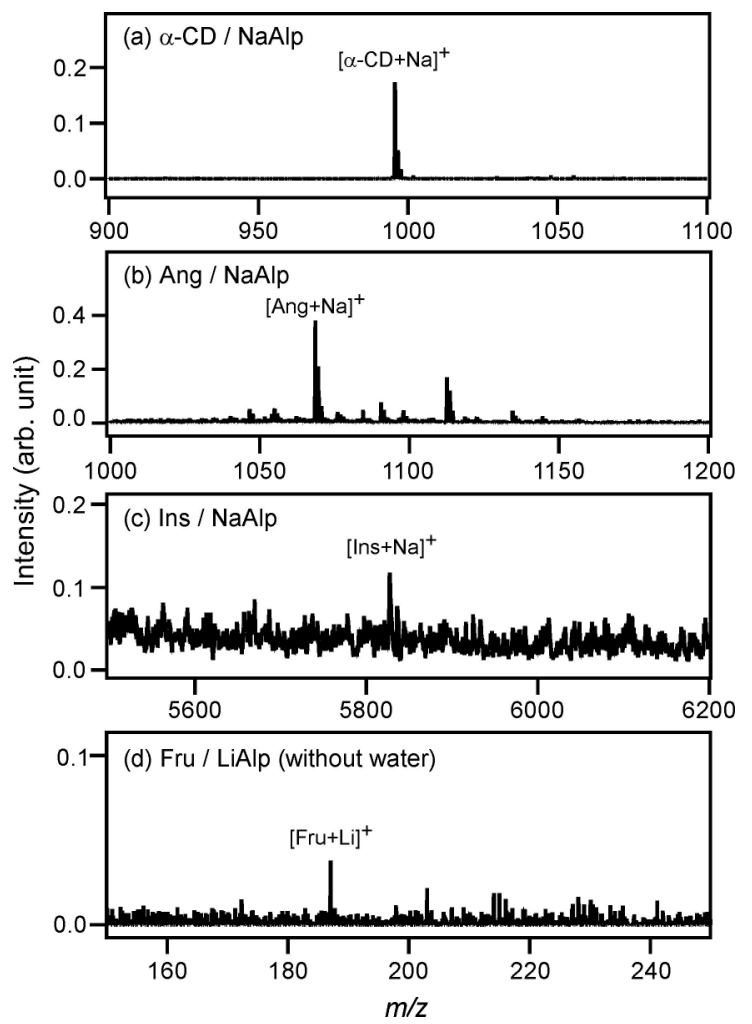

Fig. 4 Mass spectra of (a) $\alpha$-cyclodextrin ( $\alpha$-CD), (b) angiotensin II (Ang), and (c) insulin (Ins) measured with NaAlp. (d) Mass spectrum of fructose (Fru) measured with LiAlp without water.

Table 1 Peak intensity of $[\mathrm{Fru}+\mathrm{M}]^{+}(\mathrm{M}=$ alkali metal cation $)$ and its standard deviation $\left(\times 10^{-3}\right)$

\begin{tabular}{lccccc}
\hline Cation & $\begin{array}{c}\text { Intensity } \\
\text { average }\end{array}$ & SD & $\begin{array}{c}\text { RSD, } \\
\%\end{array}$ & $\begin{array}{c}\text { SD } \\
\text { overall }\end{array}$ & $\begin{array}{c}\text { RSD } \\
\text { overall, \% }\end{array}$ \\
\hline $\mathrm{Li}^{+}$ & 239 & 55 & 23 & & \\
$\mathrm{Na}^{+}$ & 465 & 62 & 13 & & \\
$\mathrm{~K}^{+}$ & 214 & 50 & 23 & 41 & 27 \\
${ }^{85} \mathrm{Rb}^{+}$ & 116 & 32 & 28 & & \\
${ }^{87} \mathrm{Rb}^{+}$ & 34 & 13 & 38 & & \\
$\mathrm{Cs}^{+}$ & 93 & 34 & 37 & & \\
\hline
\end{tabular}

important role in the alkali cation adduction to analyte, the spectrum was measured without using water during sample and matrix preparation. Figure 4(d) shows the mass spectrum of Fru measured in the presence of LiAlp but not water. Although the peak of $[\mathrm{Fru}+\mathrm{Li}]^{+}$was observed, its intensity was decreased by around $16 \%$ of that in Fig. 3(a). Therefore, it was confirmed that water molecules play an important role in the alkali cation adduction to analyte. The solvation enthalpy values were $-538.2 \mathrm{~kJ} \mathrm{~mol}^{-1}$ for $\mathrm{Li}^{+},-424.3 \mathrm{~kJ} \mathrm{~mol}^{-1}$ for $\mathrm{Na}^{+},-340.3 \mathrm{~kJ} \mathrm{~mol}^{-1}$ for $\mathrm{K}^{+},-315.7 \mathrm{~kJ} \mathrm{~mol}^{-1}$ for $\mathrm{Rb}^{+}$, and $-291.5 \mathrm{~kJ} \mathrm{~mol}^{-1}$ for $\mathrm{Cs}{ }^{+20}$

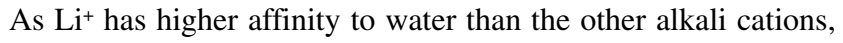
it was understood that a high peak intensity was observed for $[\text { Fru+Li }]^{+}$.

Finally, allophane loaded on zeolite surface was used as the matrix. By assuming proton relay among zeolite, allophane, and analyte, allophane was combined with zeolite, which has strong acidity, because allophane has weak acidity. In the experiments, therefore, $\mathrm{H}^{+}$-exchanged allophane (HAlp) and

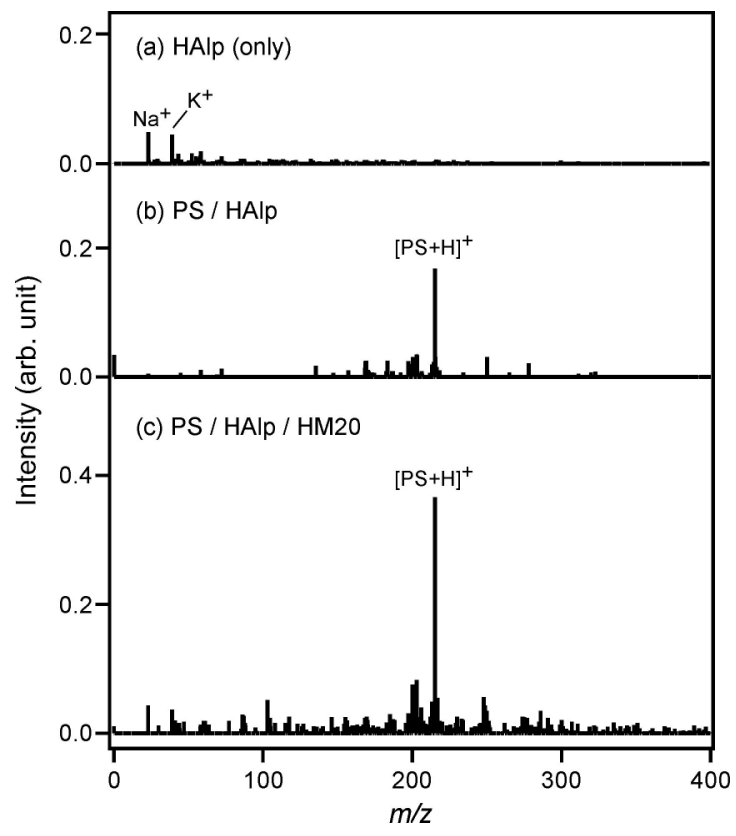

Fig. 5 (a) Mass spectrum of $\mathrm{H}^{+}$-exchanged allophane (HAlp) only. Mass spectra of proton sponge (PS) measured with (b) HAlp and (c) HAlp loaded on HM20 zeolite surface.

$\mathrm{H}^{+}$-type zeolite (HM20) were used. Figure 5(a) shows the mass spectrum of HAlp only. The fact that the peak intensities of the alkali cations $\left(\mathrm{Na}^{+}\right.$and $\left.\mathrm{K}^{+}\right)$decreased compared with the spectrum in Fig. 2(a) demonstrated that the proton exchange of allophane proceeded smoothly. To investigate proton relay among zeolite, allophane, and analyte, proton sponge (1,8-bis(dimethylamino)naphthalene; PS) was used as the analyte. Figure 5(b) shows the spectrum of PS measured with HAlp only. The peak of $[\mathrm{PS}+\mathrm{H}]^{+}$was observed at $\mathrm{m} / \mathrm{z}=215$, whereas the peak of $\mathrm{Na}^{+}$- or $\mathrm{K}^{+}$-adducted analyte was not observed. This result also confirmed that the proton exchange of allophane proceeded well. Figure 5(c) shows the spectrum of PS measured with HAlp loaded on HM20 surface. Although the intensities of noise peaks increased, the peak of $[\mathrm{PS}+\mathrm{H}]^{+}$also increased compared with that in Fig. 5(b); the peak intensity of $[\mathrm{PS}+\mathrm{H}]^{+}$became almost 2.2 times larger by using zeolite support. Because there was no proton source for PS other than zeolite, allophane, and residual solvent, it was possible to consider that the proton used for the ionization of PS came from zeolite. Therefore, it was understood that proton relay among zeolite, allophane, and analyte was achieved as in the case of our previous research using organic and inorganic matrix molecules and zeolite. ${ }^{16}$

\section{Conclusions}

Allophane was used as the matrix for MALDI MS and applied to the ionization of small molecules and insulin. The XPS spectrum showed that allophane was composed of $\mathrm{Si}, \mathrm{Al}$, and $\mathrm{O}$, and the diffuse reflectance spectrum revealed that allophane produced an absorption in the UV-vis region because of the quantum size effect. The laser desorption ionization mass spectra of cation-exchanged allophane indicated that the cation exchange proceeded smoothly with increasing period of alkali metals. Fructose was measured as an analyte using each alkalication-exchanged allophane as the matrix. Contrary to the 
measurements using allophane itself, the peak intensity of fructose decreased with increasing period of alkali cations. The applicability of allophane to high molecular weight compounds was also confirmed by measuring cyclodextrin, angiotensin II, and insulin. Therefore, it was concluded that allophane could be used as a matrix for MALDI MS of small molecules as well as relatively high molecular weight compounds. Then, a combination of allophane with zeolite was examined by assuming proton relay among allophane, zeolite, and analyte. As a result of proton supply from zeolite to allophane, the peak intensity of the proton sponge (1,8-bis(dimethylamino)naphthalene) was enhanced by almost 2.2 times.

\section{Acknowledgements}

T. F. acknowledges a Grant-in-Aid for Scientific Research (B) (No. 15H03772) from the Japan Society for the Promotion of Science. This work was partly supported by the research program "Network Joint Research Center for Materials and Devices", Japan.

\section{References}

1. K. Tanaka, H. Waki, Y. Ido, S. Akita, Y. Yoshida, and T. Yoshida, Rapid Commun. Mass Spectrom., 1988, 2, 151.

2. E. P. Go, J. V. Apon, G. Luo, A. Saghatelian, R. H. Daniels, V. Sahi, R. Dubrow, B. F. Cravatt, A. Vertes, and G. Siuzdak, Anal. Chem., 2005, 77, 1641.

3. T. R. Northen, O. Yanes, M. T. Northen, D. Marrinucci, W. Uritboonthai, J. Apon, S. L. Golledge, A. Nordström, and G. Siuzdak, Nature, 2007, 449, 1033.
4. S. A. Trauger, E. P. Go, Z. Shen, J. V. Apon, B. J. Compton, E. S. P. Bouvier, M. G. Finn, and G. Siuzdak, Anal. Chem., 2004, 76, 4484.

5. J. Wei, J. M. Buriak, and G. Siuzdak, Nature, 1999, 399, 243.

6. Y.-F. Huang and H.-T. Chang, Anal. Chem., 2006, 78, 1485.

7. X. Wen, S. Dagan, and V. H. Wysocki, Anal. Chem., 2007, 79, 434.

8. H. Komori, R. Hashizaki, I. Osaka, T. Hibi, H. Katanoa, and S. Taira, Analyst, 2015, 140, 8134.

9. T. Watanabe, H. Kawasaki, T. Yonezawa, and R. Arakawa, J. Mass Spectrom., 2008, 43, 1063.

10. T. Watanabe, K. Okumura, H. Kawasaki, and R. Arakawa, J. Mass Spectrom., 2009, 44, 1443.

11. S. Kjellstro and O. N. Jensen, Anal. Chem., 2004, 76, 5109.

12. T. Kobayashi, H. Kawai, T. Suzuki, T. Kawanishi, and T. Hayakawa, Rapid Commun. Mass Spectrom., 2004, 18, 1156.

13. C. Koster, John A. Castoro, and C. L. Wilkins, J. Am. Chem. Soc., 1992, 114, 7572.

14. T. Nishikaze and M. Takayama, Rapid Commun. Mass Spectrom., 2007, 21, 3345.

15. S. Yamaguchi, T. Fujita, T. Fujino, and T. Korenaga, Anal. Sci., 2008, 24, 1497.

16. Y. Komori, H. Shima, T. Fujino, J. N. Kondo, K. Hashimoto, and T. Korenaga, J. Phys. Chem. C, 2010, 114, 1593.

17. S. Uehara, Nendo Kagaku, 2000, 40, 100.

18. J. Suzuki and T. Fujino, Anal. Sci., 2012, 28, 901.

19. R. Osuga, T. Yokoi, K. Doitomi, H. Hirao, and J. N. Kondo, J. Phys. Chem. C, 2017, 121, 25411.

20. Y. Iwasawa, "Kagaku Binran Kisohen II" (in Japanese), 2005, Maruzen, Tokyo. 